\title{
Audit Sistem Informasi Pengadaan Barang dan Jasa Sekolah (SipLah) Menggunakan Framework COBIT 5.0
}

\author{
Donny Fernando ${ }^{[1]}$, Zaenal Muttaqin ${ }^{[2]}$, Dentik Karyaningsih ${ }^{[3]}$ \\ Program Studi Sistem Informasi ${ }^{[1][2]}$, Program Studi Teknik Informatika ${ }^{[3]}$ \\ Fakultas Teknik Informasi Universitas Serang Raya \\ Jl. Raya Cilegon No.Km. 5, Taman, Drangong, Kec. Taktakan, Kota Serang, Banten \\ mr.donny2008@gmail.com ${ }^{[1]}$, d.zaey.vu@gmail.com ${ }^{[2]}$, karya.tiek@gmail.com ${ }^{[3]}$
}

\begin{abstract}
Information Systems Audit is a process to determine whether a software company uses has been able to secure assets, maintain data integrity, drive the achievement of organizational goals effectively and use resources efficiently. This study aims to evaluate the effectiveness of the Sistem Informasi Pengadaan Sekolah (SIPlah) based on the analysis of the Process Capability Level according to the framework of COBIT 5 on the use of Dana BOS. The research object taken in this study was SMP Gugus A, Lebak Regency, Banten Province. The scope of audit in this study is Domain Monitoring and Evaluate (ME). Based on the results of the audit, the Process Capability Level is 3.14. So it can be concluded that the Sistem Informasi Pengadaan Sekolah (SIPlah) at SMP Gugus A Lebak Regency has been implemented using a process that has been defined and is able to achieve the results of the process.
\end{abstract}

Keywords - information system audit, capability level, COBIT 5, SIPlah, Dana BOS

Abstrak-Audit Sistem Informasi merupakan proses untuk menentukan apakah sebuah software yang digunakan perusahaan telah dapat mengamankan aset, memelihara integritas data, dapat mendorong pencapaian tujuan organisasi secara efektif dan menggunakan sumberdaya secara efisien. Penelitian ini bertujuan untuk mengevaluasi efektifitas Sistem Informasi Pengadaan Sekolah (SIPlah) berdasarkan analisis dari Process Capability Level sesuai kerangka kerja dari COBIT 5 terhadap penggunaan dana BOS. Object penelitian yang diambil dalam penelitian ini adalah SMP Gugus A Kabupaten Lebak Provinsi Banten. Ruang lingkup Audit di penelitian ini adalah Domain Monitoring dan Evaluate (ME). Berdasarkan hasil audit dihasilkan tingkat kematangan atau Process Capability Level adalah 3,14. Sehingga dapat disimpulkan bahwa Sistem Informasi Pengadaan Sekolah (SIPlah) pada SMP Gugus A Kabupaten Lebak telah diimplementasikan menggunakan proses yang telah terdefinisi dan mampu untuk mencapai hasil dari proses.

Kata Kunci-audit sistem informasi, capability level, COBIT 5, SIPlah, Dana BOS

\section{PENDAHULUAN}

Dana Bantuan Operasional Sekolah (BOS) adalah bantuan pendidikan berbentuk dana yang diberikan Pemerintah kepada sekolah dan madrasah di seluruh Indonesia untuk kepentingan nonpersonalia. [1],[2] Dana BOS tersebut dapat digunakan untuk memenuhi berbagai kegiatan sekolah seperti menyediakan alat belajar mengajar, membayar gaji guru, mengembangkan perpustakaan dan lain sebagainya. Dana BOS diluncurkan pertama kali pada bulan Juli tahun 2005.[2]Dalam proses penyaluran dana BOS, tak dapat dipungkiri terdapat berbagai masalah dan juga terjadinya potensi kesalahan dalam penggunaan dana BOS tersebut,[3] sehingga pada tahun 2019 pemerintah meluncurkan Sistem Informasi Pengadaan Sekolah (SIPLah)

SIPLah adalah inovasi dalam pengadaan barang/jasa Satuan Pendidikan untuk meningkatkan transparansi dan kemudahan bagi Satuan Pendidikan (Satdik) dalam administrasi dan pelaporan serta bagi UMKM untuk turut serta hadir sebagai penyedia barang dan jasa di SIPLah.[4] SIPlah memberikan kemudahan kepada sekolah untuk pengelolaan dana BOS, sehingga dana BOS dapat digunakan secara transparan, mulai dari perencanaan hingga pelaporan. [5] Dan SIPLah bertujuan agar pihak sekolah dapat lebih mudah, efektif, aman dan efisien dalam melaksanakan prosespengadaan barang dan jasa (PBJ).

Penelitian ini dilakukan pada tahun 2020 dan ketika penelitian ini dilakukan belum ditemukan laporan atau dokumentasi resmi tentang seberapa besar efektifitasnya terhadap Pengadaan Barang dan Jasa (PBJ) di sekolah. Hal itu diwajarkan sebab sistem ini masih tergolong baru. Berawal dari dasar pemikiran tersebut kemudian penelitian ini dilakukan, dan bertujuan untuk mengetahui sejauh mana tingkat Efektivitas Sistem SIPlah terhadap Pembelian barang dan Jasa menggunakan dana yang bersumber dari dana BOS.

Penelitian ini dilakukan di SMP GUGUS A Kabupaten Lebak yang mencakup 11 Sekolah diantaranya SMPN 1 Cipanas, SMPN 2 Cipanas, SMPN 3 Cipanas, SMPN Satap 4 Cipanas, SMPN Satap 5 Cipanas, SMPS Mahida, SMPS Daaruttaufiqiya, SMPN 1 Lebakgedong, SMPN Satap 2 Lebakgedong (daerah khusus), SMPN Satap 3 Lebakgedong (daerah khusus) dan SMPS Al Mujahid.[6] Dan tenggang waktu yang diberikan dalam penelitian ini dimulai dari bulan Maret hingga Agustus 2020. Kepala Sekolah Berserta Dewan 
Guru menjadi orang-orang yang terlibat dalam penelitian.

Penelitian terdahulu telah melakukan Audit untuk dapat mengukur tata kelola proses aplikasi pengadaan barang dan jasa pada salah satu universitas di Indonesia menggunakan metode COBIT 4.1 dan proses ini dilakukan untuk memberikan masukan dan perbaikan terhadap proses kerja yang berjalan. [8]

Sedangkan pada penelitian ini dilakukan menggunakan prosedur COBIT 5 Domain ME (Monitor \& Evaluate). Melakukan monitoring dan evalusi pada sistem SIPlah dengan menyebarkan kuesioner atau pun wawancara terhadap objek penelitian sesuai dengan standar COBIT 5, yang dimana nilai dari hasil yang didapat dapat dilakukan pengujian sistem dengan menggunakan tingkat kemampuan (capability level)dan menggunakan spider chart [7] sebagai salah satu metode implementasi.

Penelitian terdahulu telah melakukan Audit untuk dapat mengukur tata kelola proses aplikasi pengadaan barang dan jasa pada salah satu universitas di Indonesia menggunakan metode COBIT 4.1 dan proses ini dilakukan untuk memberikan masukan dan perbaikan terhadap proses kerja yang berjalan. [8]

Hasil penelitian ini diharapkan dapat bermanfaat kepada masyarakan, pemerintah dan stakeholder pendidikan yang memiliki kepentingan terhadap dana BOS dan penggunaan sistem SIPLah dilingkungan sekolah.

\section{Metode Penelitian}

Penelitian ini adalah penelitian terapan, fokus penelitian ini adalah untuk menguji seberapa efektifnya SIPlah agar hasilnya bisa diterapkan sebagai dasar referensi untuk meningkatkan efektifitas penggunaan Dana BOS terhadap keperluan pembelian barang dan jasa pada kondisi sekarang ataupun yang akan datang (berkesinambungan).

Studi pendahuluan telah dilakukan untuk mempersiapkan penelitian ini dengan menyiapkan beberapa teori pendukung tentang COBIT 5.0 dan Process Assessment Model (PAM) yang digunakan untuk melakukan penelitian ini.

Control Objectives for Information and Related Technology (COBIT) telah menjadi standar internasional untuk Tata Kelola TI, yang disiapkan oleh ISACA dan ITGI pada tahun 1996.[9] COBIT merupakan rangkaian dokumentasi praktik terbaik untuk Tata Kelola TI yang digunakan untuk membantu auditor, pengguna, pemilik proses bisnis, dan manajemen untuk mengendalikan celah risiko bisnis, kebutuhan pengendalian, dan masalah Teknis TI.

COBIT 5 yang merupakan framework terbaru yang dirilis COBIT pada 2012 yang dilengkapi beberapa fitur tambahan. COBIT 5 dilengkapi dengan 5 prinsip (lihat gb.1) dan 7 enablers[10] yang diberikan untuk melengkapi fitur yang sebelumnya COBIT 4.1. [11]

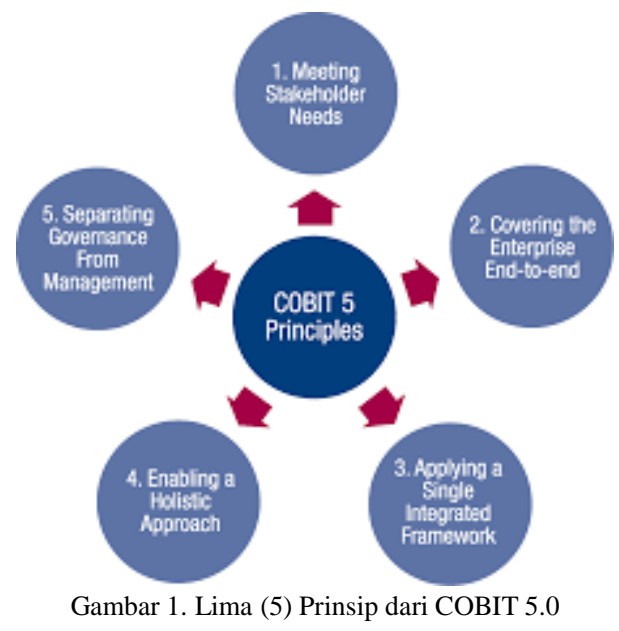

Pada COBIT 5 diperkenalkan unsur VAL IT. [12] Val IT adalah sebuah kerangka tata kelola yang meliputi prinsip penerimaan dari proses pendukung yang berhubungan dengan evaluasi dan seleksi yang memungkinkan investasi Teknologi Informasi (TI) dalam bisnis, melakukan realisasi dari manfaat, dan memberikkan nilai dari investasi tersebut. Terdapat juga pemisahan jelas antara proses tata kelola dan proses manajemen yang terdapat pada COBIT 5.

Sehingga bisa disimpulkan COBIT 5 dibangun berdasarkan pengembangan dari COBIT 4.1 dengan mengintegrasikan Val IT dan Risk IT dari ISACA, ITIL, dan standar-standar yang relevan dari ISO.

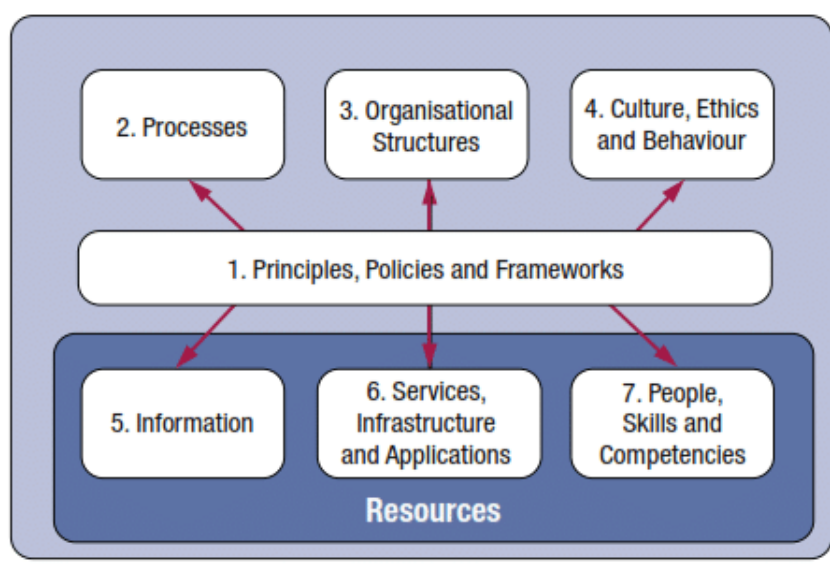

Gambar 2. Tujuh (7) proses enabler

COBIT mendukung tata kelola TI dengan menyediakan kerangka kerja untuk mengatur keselarasan TI dengan bisnis.Selain itu, kerangka kerja juga memastikan bahwa TI memungkinkan bisnis, memaksimalkan keuntungan, resiko TI dikelola secara tepat, dan sumber daya TI digunakan secara bertanggung jawab (Tanuwijaya dan Sarno, 2010).

Untuk dapat memahami kerangka kerja COBIT 5 perlu diketahui apa saja yang menjadi faktor penggerak pada COBIT 5 apa saja proses yang terdapat didalamnya dan bagaimana indikator penilaian terhadap process assessments model di COBIT 5. 
Aktivitas Teknologi Informasi pada COBIT 5 didefinisikan pada dua dimensi utama yaitu Governance dan Management.

\section{1) Governance}

Terdiri atas lima domain dalam proses Evaluate, Direct, andMonitor (EDM).

\section{2) Management}

Terdiri atas 4 domain utama yang bertanggung jawab pada area Plan, Build, Run, and Monitor (PBRM) yaitu

- Align, Plan, and Organise (APO)

- Build, Acquire, and Implement (BAI)

- Deliver, Service, and Support (DSS)

- $\quad$ Monitor, Evaluate, and Assess (MEA)

Gambar 3 dibawah merupakan gambaran dimensi dari COBIT 5.

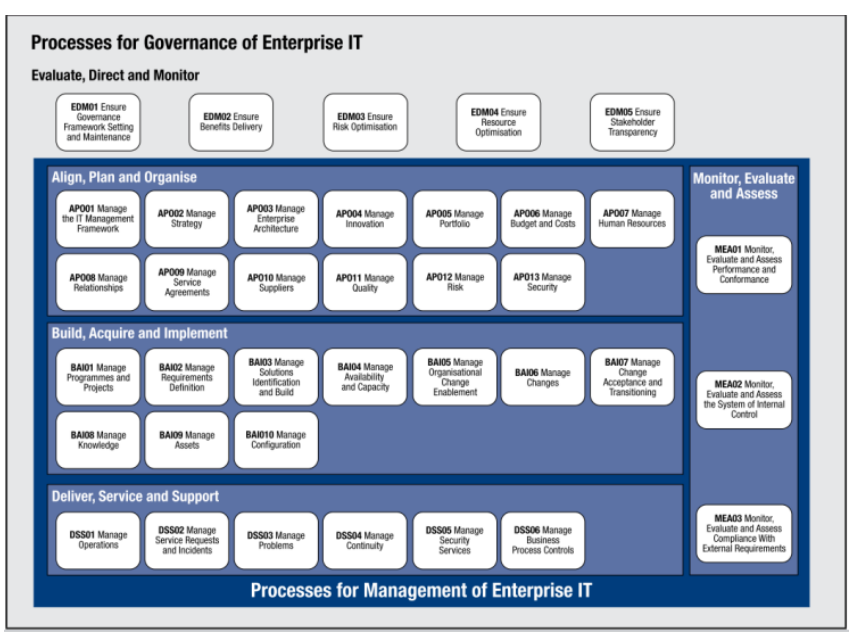

Gambar 3. Area Utama Management dan Goverment Cobit

Model penilaian yang digunakan pada penelitian ini adalah COBIT 5 Process Assessment Model (PAM). Process Assessment Model (PAM) merupakan model untuk mengukur tingkat kapabilitas proses pada COBIT 5. Metode pengukuran kapabilitas ini dibangun berdasarkan standar internasional ISO/IEC 15504.[13]

ISO / IEC 15505 mendefinisikan pengukuran untuk penilaian kemampuan proses kerangka kerja COBIT. Proses kapabilitas didefinisikan pada 6 level dimulai dari poin 0 sampai 5, yang merepresentasikan peningkatan kapabilitas dari proses implementasi.[14]

Berikut penjelasan proses kapabilitas level: Tabel 1

TABEL 1. CAPABILITY LEVEL

\begin{tabular}{|c|l|l|}
\hline Level & Value & \multicolumn{1}{c|}{ Description } \\
\hline 0 & Incomplete & Belum diimplementasikan \\
\hline 1 & Performed & Telah mencapai tujuan dari proses tersebut \\
\hline 2 & Managed & Level 1 telah diterapkan dengan kinerja produk \\
\hline
\end{tabular}

\begin{tabular}{|c|l|l|}
\hline & & $\begin{array}{l}\text { yang tepat ditetapkan, dikendalikan, dan } \\
\text { dipelihara. }\end{array}$ \\
\hline 3 & Established & $\begin{array}{l}\text { Level 2 telah diterapkan yang mampu } \\
\text { mencapai hasil dari proses tersebut }\end{array}$ \\
\hline 4 & Predictable & $\begin{array}{l}\text { Proses yang ditetapkan di Level 3 itu } \\
\text { beroperasi berdasarkan batasan yang } \\
\text { ditentukan. }\end{array}$ \\
\hline 5 & Optimized & $\begin{array}{l}\text { Proses yang diprediksi pada level 5 diperbaiki } \\
\text { untuk memenuhi tujuan bisnis saat ini yang } \\
\text { relevan dan terarah }\end{array}$ \\
\hline
\end{tabular}

Langkah-langkah yang dilakukan untuk menyelesaikan permasalahan di penelitian ini diawali dengan melakukan observasi lapangan. Observasi lapangan ini dilakukan untuk mengetahui apa permasalahannya, agar ditemukan masalah sebenarnya yang dapat diselidiki secara tuntas.

Kemudian selanjutnya dilakukan Studi Pustaka untuk mempelajari framework COBIT 5 dan Process Assessment Model (PAM) yang digunakan untuk menyelesaikan permasalahan di penelitian ini.

Tahapan berikutnya dilakukan pengambilan data dengan cara menyebarkan kuisioner kepada Kepala Sekolah, Bendahara dan Dewan Guru di SMP Gugus A Kabupaten Lebak Banten.

Setelah data terpenuhi selanjutnya dilakukan pengolahan datauntuk menentukan sejauh mana keefektifan dengan melakukan perhitungan tingkat kemampuan (capability level) menggunakan framework dari COBIT 5.

Setelah melakukan perhitungan capability level, barulah kemudian dikeluarkan kesimpulan untuk di indentifikasi sejauh mana efektifitas penggunaan SIPlah terhadap pembelian barang dan jasa (PBJ) yang telah diimplementasikan sejauh ini pada sekolah SMP Gugus A Kabupaten Lebak Provinsi Banten.

Adapun gambaran tahapan-tahapan penelitian ini dapat dilihat pada gambar 4 di bawah ini.

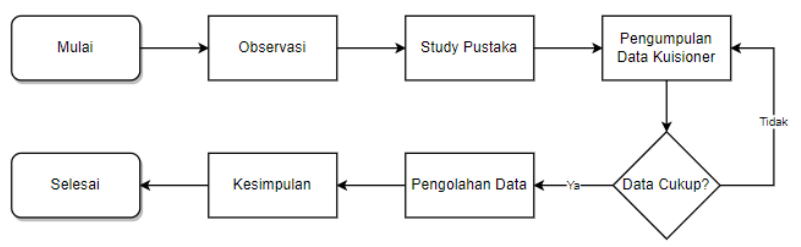

Gambar 4. Tahapan Penelitian

\section{HASIL DAN PEMBAHASAN}

Penelitian ini dilakukan melalui studi kasus di mana lokasi penelitian ini di SMP Gugus A Kabupaten Lebak, penelitian dilakukan dari bulan maret hingga agustus 2020 dimulai dari menyiapkan bahan penelitian hingga pembuatan laporan penelitian. Studi ini mengukur tingkat kematangan penggunaan proses sistem SIPlah yang ada di Kementerian Pendidikan dalam rangka mencapai tujuan institusional didasarkan pada COBIT framework versi 5. Penelitian ini merupakan penelitian deskriptif, penelitian ini terdiri dari data primer dan sekunder. 
Adapun keseluruhan subjek penelitian (Populasi) dari penelitian ini adalah kepala sekolah, bendahara dan dewan guru SMP Gugus A Kabupaten Lebak periode 2020/2021 dengan jumlah total 137. Menurut Arikunto (2006:112) mengatakan bahwa "apabila subjeknya kurang dari seratus, lebih baik diambil semuanya sehingga penelitiannya merupakan populasi. Tetapi, jika jumlah subjek lebih besar dari seratus, dapat diambil $10-15 \%$ atau $15-25 \%$ atau lebih sehingga merupakan penelitian sample yang mewakili keseluruhan populasi".

Berdasarkan pada pendapat tersebut, maka pengambilan sampel dalam penelitian ini adalah $25 \%$ dari jumlah populasi yang ada, karena populasi melebihi 100 yaitu 137. Berarti 137 $\mathrm{X} 25 \% / 100=34$, Jadi sampel yang digunakan dalam penelitian ini berjumlah 34 atau lebih.

Data primer yang digunakan dalam penelitian ini diperoleh penulis dari wawancara yang didasarkan pada instrumen penelitian dengan menggunakan kuisioner, survei dan observasi. Peneliti mengambil Sample sebagai data primer 35 orang, yang terdiri dari perwakilan sekolah, baik kepala sekolah, bendahara, atau dewan guru di SMP Gugus A Kabupaten lebak.

Sedangkan data sekunder, peneliti merujuk kepada jurnaljurnal referensi penelitian terdahulu yang memiliki kaitan dengan topik yang diambil peneliti.

\section{A. Data Responden}

Data responden dalam penelitian ini berdasarkan dari 3 kelompok yaitu Kepala Sekolah, Bendahara dan Perwakilan dewan guru. Sample yang didapat dalam penelitian ini meliputi diantaranya 11 orang (43\%) Kepala Sekolah yang bertanggung jawab secara langsung dalam pengoperasian SIPlah, Bendahara yang bertanggung jawab perihal keuangan sekolah terdiri dari 9 orang (26\%), sedangkan 15 Orang lainnya atau (43\%) terdiri dari perwakilan dewan guru.

Gambar grafik di bawah ini memberikan gambaran penyebaran data responden berdasarkan kelompok data responden.

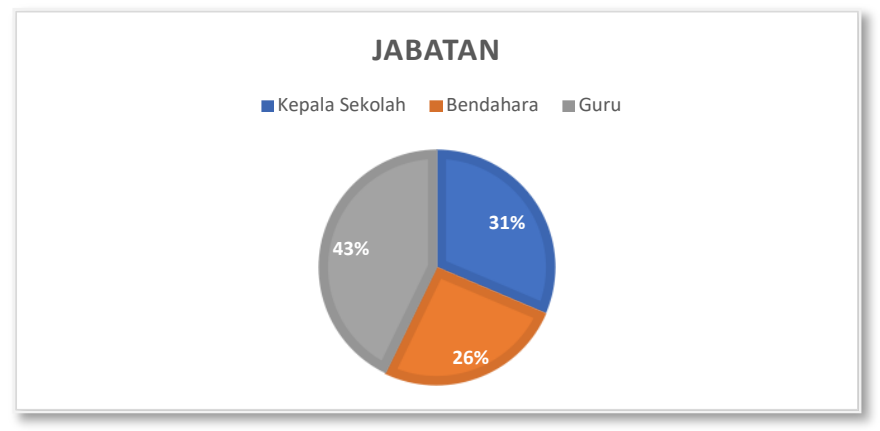

Gambar 5. Kelompok Data Responden

Penelitian pada kasus ini jumlah responden yaitu 35 orang, dengan grafik yang berwarna biru adalah kepala sekolah, warna orange menunjukan bendahara, dan warna abu-abu menunjukan jabatan adalah guru.

Peneliti mendapatkan jawaban data melalui 35 responden dari 11 Sekolah, diantaranya SMPN 1 Cipanas, 5 Responden (14\%), SMPN 2 Cipanas, 4 Responden (11\%), SMPN 3 Cipanas, 5 Responden (14\%), SMPN Satap 4 Cipanas, 4 Responden (11\%), SMPN Satap 5 Cipanas, 3 Responden (9\%), SMPS Nurul Madany, 3 Responden (9\%), SMPS Mahida, 1 Responden (3\%), SMPS Daaruttaufiqiyah, 1 Responden (3\%), SMPN 1 Lebakgedong, 3 Responden (9\%), dan SMPS Al Mujahid, 3 Responden (9\%)

Dapat di lihat pada gambar 6 di bawah ini.

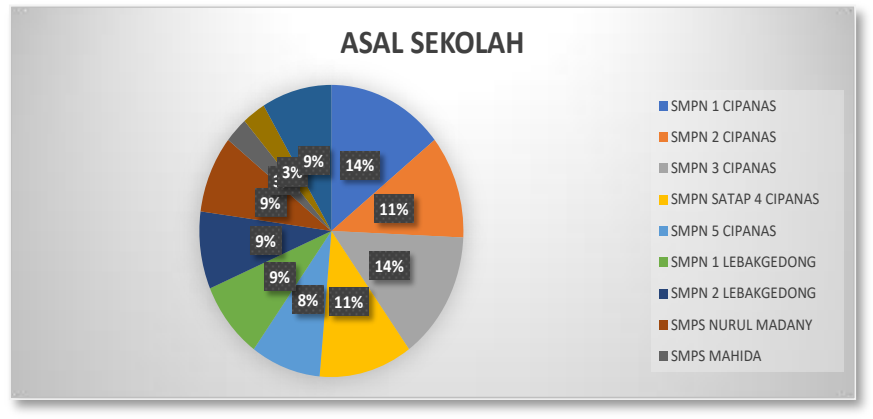

Gambar 6. Asal Sekolah Responden

Penyebaran Kuesioner kepada para responden dengan menggunakan 2 metode, yang pertama menggunakan metode Luring (Luar Jaringan) atau datang langsung ke beberapa sekolah dan rata-rata sekolah menggunakan sistem Daring (Dalam Jaringan).

\section{B. Rekapitulasi Capability Model}

Pada penelitian ini, peneliti menggunakan capability level sebagai alat ukur data primer terhadap jawaban responden dari kuesioner yang dibuat berdasarkan framework COBIT 5. Kuesioner ini berisi pernyataan-pernyataan berdasarkan domain Monitor and Evaluate (ME), yaitu:

\section{1) Monitor and Evaluate System Performance (ME01)}

Pada proses ini berisi pernyataan mengenai proses-proses yang berkaitan dengan performa daripada sistem, tentang bagaimana kinerja dari Sistem SIPlah tersebut. Pada proses ini terdiri dari 5 pernyataan

\section{2) Monitor System of Internal Control (ME02)}

Pada proses ini berisi pernyataan mengenai proses-proses yang berkaitan dengan kegiatan pengawasan sistem pengendalian internal yaitu tentang bagaimana kegiatan penggunaan sistem tersebut dilakukan serta dinilai keefektifitasannya. Pada proses ini terdiri dari 6 pernyataan

\section{3) Monitor and Evaluate Compliance with Requirements} (ME03)

Pada proses ini berisi pernyataan mengenai proses-proses yang berkaitan dengan kegiatan pengawasan dan evaluasi SIPlah terhadap kebutuhan, perihal pengadaan barang dan jasa di sekolah yang harus dipenuhi. Dalam hal ini meliputi tentang bagaimana Sekolah di Gugus A mengidentifikasi kebutuhan dan ketetapan lainnya. Pada proses ini terdiri dari 6 pernyataan

4) Monitor and Evaluate Governance System (ME04) 
Pada Proses ini berisi pernyataan mengenai proses-proses yang berkaitan dengan pengawasan dan evaluasi pengelolaan terhadap SIPlah tentang bagaimana user atau SDM yang tersedia dapat mengelola SIPlah dengan baik dan mengkomunikasikan perubahan tersebut kepada semua SDM yang terkait, dan mengatasi kemudian melaporkan masalah ketidakpatuhan yang terjadi. Pada proses ini terdiri dari 6 pernyataan

Kondisi kemampuan Sistem SIPlah saat ini dapat diidentifikasi melalui analisis tingkat kemampuan yang mengacu pada tingkat kemampuan COBIT khususnya monitoring dan evaluasi. Analisis tingkat kemampuan dapat diperoleh dari penyebaran kuesioner. Adapun jumlah responden pada penelitian ini sejumlah 35 orang.

Berikut rekapitulasi tingkat kemampuan berdasarkan data yang diterima dari responden, rekapitulasi hasil kuesioner terlihat pada tabel 2 dibawah ini.

TABEL 2. REKAPITULASI BERDASARKAN RATA-RATA SUB PROSESS

\begin{tabular}{|c|l|c|}
\hline Domain & \multicolumn{1}{|c|}{ Process } & $\begin{array}{c}\text { Rata-rata } \\
\text { Sub Process }\end{array}$ \\
\hline ME01 & Mengelola kinerja dan kemampuan sistem & 14,86 \\
\hline ME02 & $\begin{array}{l}\text { Memastikan pengendalian SIPLah berjalan } \\
\text { dengan baik }\end{array}$ & 17,31 \\
\hline ME03 & $\begin{array}{l}\text { Memastikan SIPLah bisa memenuhi } \\
\text { kebutuhan sekolah }\end{array}$ & 18,49 \\
\hline ME04 & $\begin{array}{l}\text { Memastikan pengguna dapat menggunakan } \\
\text { sistem SIPLah dengan baik }\end{array}$ & 21,83 \\
\hline
\end{tabular}

Tabel diatas menjelaskan hasil rekapitulasi setiap indikator dengan rata-rata sub proses yang didapat. Domain dengan rata-rata tertinggi terdapat pada ME04 dengan nilai rata-rata 21,83, kemudian ME03 dengan nilai rata-rata 18,49 dan ME02 dengan nilai rata-rata yaitu 17,31 sedangkan rata-rata terkecil terdapat pada ME01 dengan nilai bobot 14,86.

Angka rata-rata setiap sub proses ini dihitung dengan menjumlahkan nilai setiap pertanyaan dari setiap sub proses kemudian dibagi dengan total responden.

Setelah mendapatkan hasil rata-rata setiap domain, untuk mendapatkan nilai capabiliy nilai rata-rata dibagi sesuai dengan total jawaban setiap sub domain.

Secara umum, setelah dilakukan rekapitulasi proses perhitungan dengan membaginya dengan jumlah pernyataan setiap sub domain, dapat dijelaskan bahwa dalam domain monitoring and evaluate (ME), ada 1 proses yang mempunyai tingkat kematangan 4 (Predictable Process) dan 3 proses lainnya mempunyai tingkat kematangan 3 (Established Process) seperti terdeskripsikan pada tabel 3 Dibawah ini.

TABEL 3. CURRENT MATURITY DOMAIN ME

\begin{tabular}{|c|c|c|}
\hline Domain & Index & Level \\
\hline ME01 & 2,97 & 3 \\
\hline ME02 & 2,89 & 3 \\
\hline ME03 & 3,08 & 3 \\
\hline ME04 & 3,64 & 4 \\
\hline
\end{tabular}

Tabel yang terdapat pada tabel3 merupakan penilaian yang mengacu pada Capability Level. Score ini berasal dari rata-rata capability score atas indicator setiap subdomain. Keempat score tersebut akan dijumlahkan dan dibagi dengan banyaknya subdomain untuk didapatkan rata-rata atau yang biasa disebut dengan capability score.

Maka didapatkan nilai tingkat kemampuan (Capability Level) saat ini sebesar 3,14 pada rentang 0-5. Nilai tingkat kemampuan tertinggi terdapat pada domain ME04 yaitu sebesar 3,64, sedangkan nilai terendah terdapat pada domain ME02 yaitu sebesar 2,89.

Sedangkan, skala pembulatan indeks bagi pemetaan ketingkat model capability terdapat pada tabel4 berikut ini.

TABEL 4. SKALA PEMBUATAN INDEKS

\begin{tabular}{|c|l|}
\hline Skala Pembulatan & \multicolumn{1}{|c|}{ Tingkat Model Kapabilitas } \\
\hline $4,51-5,00$ & 5 -Optimizing \\
\hline $3,51-4,50$ & 4 -Predictable \\
\hline $2.51-3,50$ & 3 - Established \\
\hline $1,51-2,50$ & 2 - Managed \\
\hline $0,51-1,50$ & 1 - Performed \\
\hline $0,00-0,50$ & 0 - Incomplete \\
\hline
\end{tabular}

Dari hasil pengukuran maka dihasilkan gambaran tentang tingkat efektifitas penggunaan SIPlah yang telah dilakukan yang disajikan pada tabel 5 dibawah ini.

TABEL 5. HASIL PENGUKURAN TINGKAT KEMAMPUAN

\begin{tabular}{|c|c|c|}
\hline Domain & $\begin{array}{c}\text { Index Sub } \\
\text { Process }\end{array}$ & Tingkat Model Kapabilitas \\
\hline ME01 & 2,97 & Established Process \\
\hline ME02 & 2,89 & Established Process \\
\hline ME03 & 3,08 & Established Process \\
\hline ME04 & 3,64 & Predictable Process \\
\hline
\end{tabular}

Pencapaian saat ini masih belum sesuai dari harapan yang akan dicapai. Hal tersebut dapat dilihat pada tabel pencapaian berdasarkan domain. Grafik hasil pengukuran tingkat kematangan pada sistem SIPlah menggunakan framework COBIT 5 pada SMP Gugus A Kabupaten Lebak, dapat dilihat pada tabel 6 berikut ini.

TABEL 6. GAP MATURITY LEVEL

\begin{tabular}{|c|c|c|c|}
\hline \multirow{2}{*}{ Domain } & \multicolumn{3}{|c|}{ Tingkat Kematangan } \\
\cline { 2 - 4 } & Saat ini $(\boldsymbol{A s}$ is $)$ & Harapan $($ To be $)$ & Gap \\
\hline ME01 & 2,97 & 4.00 & 1,03 \\
\hline ME02 & 2,89 & 4.00 & 1,11 \\
\hline ME03 & 3,08 & 4.00 & 0,92 \\
\hline ME04 & 3,64 & 4.00 & 0,36 \\
\hline
\end{tabular}

Pada tabel 6 diatas, Menunjukan data dari setiap domain ME terhadap efektifitas penggunaan Sistem SIPlah masih belum sesuai harapan. Nilai rata-rata Gap dari domain ME01, ME02, ME03 dan ME04 menunjukan 0,86, dengan nilai gap tertinggi di ME 02, 1,11 dan terendah ME04 0,36. Semakin rendah nilai gap maka dapat disimpulkan bahwa sistem yang berjalan mulai menuju efektifitas yang sesuai dengan nilai harapan.

Berdasarkan tabel diatas maka Evaluation and Internal Control adalah bagian yang menjadi perhatian dari SMP Gugus A Kabupaten Lebak. Dan hal yang mejadi rekomendasi 
yaitu perlunya ditingkatkan evaluasi terhadap mitra SIPLah dan pengendalian internal terhadap kemudahan penggunaan. Selain Evaluation and Internal Control hal yang dapat menjadi rekomendasi untuk ditingkatkan adalah Monitoring and System Performance, pada domain ini ditemukan bahwa masih ada pengguna yang belum nyaman dan mudah untuk mengoperasikan sistem ini.

Adapun nilai capability level yang diimplementasikan menjadi spider chart dapat dilihat pada gambar dibawah ini.

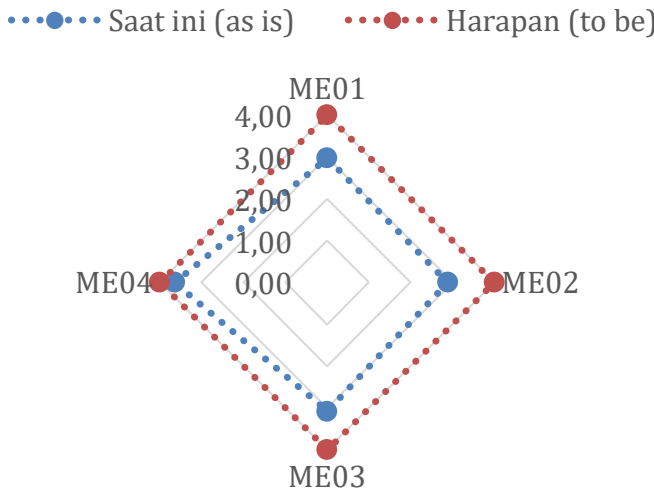

Gambar 7. Spider Chart Capability Level

Hasil audit Sistem Informasi Pengadaan Sekolah (SIPlah) terhadap efektifitas penggunaan Dana Bos, maka sub domain rata-rata dari hasil perhitungan capability level, diperlihatkan pada tabel diatas. Keseluruhan capability yang diinginkan (tobe) adalah pada level 4 yaitu Managed dibandingkan dengan maturity saat ini (as-is) yang berada pada level 3,14 dalam rentang 2,51-3,50 yaitu Established Proses, dengan Tingkat Kesenjangan (Gap) berada diangka 0,86. dimana untuk mencapai efektifitas dari pada penggunaan sistem SIPlah masih ada selisih sekitar 0,86 .

\section{KESIMPULAN DAN SARAN}

\section{A. Kesimpulan}

Adapun berdasarkan hasil penelitian yang telah dilakukan, dapat disimpukan bahwa:

1) Berdasarkan proses audit Sistem InformasiPengadaan Sekolah (SIPlah) sesuai dengan prosedur COBIT 5, rata-rata capability level adalah 3,14 (Established Process) yang artinya system telah telah diimplementasikan menggunakan proses yang telah terdefinisi dan mampu untuk mencapai hasil dari proses. Meskipun masih mempunyai gap (selisih) sebesar 0,86 untuk mencapai level yang diharapkan. Oleh sebab itu berdasarkan hasil audit ini penulis merekomendasi agar dinas kependidikan perlu membantu dilakukannya pemantauan dan pengukuran secara konsisten sehingga apabila terjadi kesalahan sudah memiliki gambaran untuk dilakukannya tindakan perbaikan. Dari empat domain terdapat 1 proses sistem sudah berada dilevel 4 dan sisanya masih berada dilevel 3.
2) Capability level teredah dari empat domain yaitu ada pada proses ME02 yang berkaitan dengan pengelolaan pengendalian sistem yang mendapatkan nilai tingkat kemampuan (capability) sebesar 2,89. Berdasarkan hasil audit capability level tersebut, rekomendasi yang dapat diberikan yaitu dinas pendidikan perlu terus memantau kontrol dari pada sistem SIPlah tersebut agar kebutuhan user bisa terpenuhi dan selaras dengan strategi yang tercermin dalam prosedur dan kebijakan yang ada.

3) Proses tertinggi berada pada domain ME04 yaitu level 4 yang artinya kemampuan sekolah dalam memperoleh dan mengelola Dana BOS melalui Sistem SIPlah dilaksanakan dengan baik dan meminimalisir kebocoran dana sehingga sesuai dengan ketentuan Dinas Pendidikan dan Kebudayaan Kabupaten Lebak terhadap pengadaan barang dan jasa.

\section{B. Saran}

Adapun saran-saran yang dapat peneliti berikan untuk penelitian selanjutnya, adalah sebagai berikut:

1) Peneliti selanjutnya dapat menggunakan metode framework lainnya.

2) Menggunakan SMP Gugus berikutnya atau gugus yang lain untuk mengetahui seberapa besar pengaruh SIPlah terhadap kinerja dalam melakukan pengadaan barang dan jasa;

3) Peneliti selanjutkan harap memperhatikan dalam melakukan penyebaran dan pengumpulan data, khususnya untuk merekap data sekolah yang berada dipedalaman (susah diakses) dan terkendala tidak adanya sinyal.

\section{REFERENS}

[1] Wikipedia, "Bantuan Operasional Sekolah," Wikipedia, 2020.

https://id.wikipedia.org/wiki/Bantuan_Operasional_Seko lah.

[2] Pintek.id, "Mengenal Apa itu Dana BOS Hingga Besaran Uang yang Diterima Sekolah!," Pintek.id, 2020. https://pintek.id/blog/mengenal-apa-itu-dana-bos-hinggabesaran-uang-yang-diterima-sekolah/ (accessed Dec. 15, 2020).

[3] Pintek.id, "Kendala dan Solusi Pencairan Dana BOS $2020 \quad$ untuk Sekolah!," 2020. https://pintek.id/blog/kendala-dan-solusi-pencairan-danabos-2020-untuk-sekolah/.

[4] Kemendikbud, "SIPLah Kemendikbud Terima Penghargaan Praktik Baik Pengadaan Barang dan Jasa dari KPK," $\quad 2020$. https://siplah.kemdikbud.go.id/index.php/liputan/entry/si plah-kemendikbud-terima-penghargaan-praktik-baikpengadaan-barang-dan-jasa-dari-kpk.

[5] Kemdikbud, "Cari tahu informasi SIPLah," 
siplah.kemdikbud.go.id, 2020. https://siplah.kemdikbud.go.id/index.php/pelajari\#tentan g.

[6] Wikipedia, "Kabupaten Lebak," Wikipedia, 2000. https://id.wikipedia.org/wiki/Kabupaten_Lebak.

[7] Wikipedia, "Radar chart / Spider chart," 2000. https://en.wikipedia.org/wiki/Radar_chart.

[8] G. Ayu, T. Krisanthi, I. M. Sukarsa, and I. P. A. Bayupati, "GOVERNANCE AUDIT OF APPLICATION PROCUREMENT," vol. 59, no. 2, pp. 342-351, 2014.

[9] B. A. Bahari, F. Adnan, and B. Prasetyo, "Audit Capability Level Using COBIT 5.0: A University Customer Care Center at University of Jember," Proc. 2019 Int. Conf. Comput. Sci. Inf. Technol. Electr. Eng. ICOMITEE 2019, vol. 1, pp. 5-12, 2019, doi: 10.1109/ICOMITEE.2019.8921118.

[10] ISACA, COBIT 5 : Enabling Processes. 2012.

[11] ISACA, COBIT Five: A Business Framework for the
Governance and Manajement of Enterprise IT Using COBIT 5. 2012.

[12] P. Afzali, E. Azmayandeh, R. Nassiri, and G. L. Shabgahi, "Effective governance through simultaneous use of COBIT and val IT," ICEMT 2010 - 2010 Int. Conf. Educ. Manag. Technol. Proc., pp. 46-50, 2010, doi: 10.1109/ICEMT.2010.5657549.

[13] H. W. Jung and R. Hunter, "The relationship between ISO/IEC 15504 process capability levels, ISO 9001 certification and organization size: An empirical study," J. Syst. Softw., vol. 59, no. 1, pp. 43-55, 2001, doi: 10.1016/S0164-1212(01)00047-4.

[14] H. T. Sihotang, M. Zarlis, S. Efendi, D. Jollyta, and Husain, "Evaluation of Maturity Level of Information and Communication Technology (ICT) Governance with CobIT 5.0 Case Study: STMIK Pelita Nusantara Medan," J. Phys. Conf. Ser., vol. 1255, no. 1, pp. 0-6, 2019, doi: 10.1088/1742-6596/1255/1/012046. 